\title{
Effects of Nb-Alloying on High-Temperature Oxidation of $\mathrm{MoSi}_{2}$
}

\author{
A.A. SHARIF \\ California State University Los Angeles, Department of Mechanical Engineering \\ 5151 State University Dr., Los Angeles, CA 90032-8153, USA
}

\begin{abstract}
The effects of alloying with $0.5,1.0$, and 2.0 at. $\% \mathrm{Nb}$ on oxidation resistance of $\mathrm{MoSi}_{2}$ are investigated at temperature range of $1400{ }^{\circ} \mathrm{C}-1700{ }^{\circ} \mathrm{C}$. Rapid formation of a stable protective layer of silica resulted in a parabolic oxidation rate. The oxide layer thickness and the sample weight increased with increasing oxidation time. Impurities accelerated oxidation rate of $\mathrm{MoSi}_{2}$ only slightly, however, did not affect the rate controlling mechanism for oxidation. There was no correlation between oxidation rate and the amount of impurity. The values of activation energies for oxidation of pure $\mathrm{MoSi}_{2}$ and Nb-alloyed samples were similar to activation energy for diffusion of $\mathrm{O}_{2}$ through silica. Diffusion of $\mathrm{O}_{2}$ through the oxide scale remained the rate controlling mechanism with or without $\mathrm{Nb}$ impurity.
\end{abstract}

DOI: 10.12693/APhysPolA.125.563

PACS: 64.75.Lm

\section{Introduction}

Molybdenum disilicide $\left(\mathrm{MoSi}_{2}\right)$ has superb oxidation resistance up to $1700^{\circ} \mathrm{C}$, which makes it a great candidate for applications requiring high-temperature stability. Development of $\mathrm{MoSi}_{2}$-based alloys as ultrahigh-temperature structural materials to improve on operating temperature of Ni-based super alloys have been the focus of many investigations in the past two decades $[1,2]$. Elevating the operating temperature of gas engines above the operating temperature of superalloys would result in significant increase in efficiency, considerable cost savings, and reduction of environmentally harmful emissions. However, there are some inherent problems with the use of $\mathrm{MoSi}_{2}$-based alloys as structural materials. $\mathrm{MoSi}_{2}$ transitions from brittle to ductile are only at high temperatures $\left(\approx 900^{\circ} \mathrm{C}\right)$; it undergoes pest oxidation at temperature range of $\approx 500-800^{\circ} \mathrm{C}$; and it has inadequate strength at elevated temperatures. Various alloying approaches have proven successful in eliminating some of the problems with application of $\mathrm{MoSi}_{2}$-based alloys as structural materials. It was shown that alloying and eliminating porosity may hinder the pest oxidation problem of $\mathrm{MoSi}_{2}[3,4]$. Furthermore, ceramic reinforcements such as $\mathrm{SiC}, \mathrm{Si}_{3} \mathrm{~N}_{4}, \mathrm{WSi}_{2}$, or $\mathrm{NbSi}_{2}$ improve its mechanical properties at high temperatures [5-7].

Investigations on alloying $\mathrm{MoSi}_{2}$ with low fraction of impurities while keeping the body-centered tetragonal $\left(C 11_{b}\right)$ structure of $\mathrm{MoSi}_{2}$ have been more promising. First principles calculations have predicted enhancement in ductility of $\mathrm{MoSi}_{2}$ by substitutional alloying of $\mathrm{V}$ and $\mathrm{Nb}$ for $\mathrm{Mo}$ and $\mathrm{Mg}$ and $\mathrm{Al}$ for $\mathrm{Si}[8]$. Experimentally, unusually high strengthening was observed by substitutional Re alloying of $\mathrm{MoSi}_{2}[9]$ and concurrent low-temperature softening and high-temperature strengthening was obtained by alloying with $\mathrm{Al}$ or $\mathrm{Nb}$ within their solubility limit in $\mathrm{MoSi}_{2}$ [10-14]. Nb was found to be the most potent alloying element in improving mechanical properties of $\mathrm{MoSi}_{2}$. Addition of 1 at.\% $\mathrm{Nb}$ to $\mathrm{MoSi}_{2}$ was found to lower its brittle-to-ductile transition temperature to room temperature [10]. At very high temperatures $\left(\approx 1600{ }^{\circ} \mathrm{C}\right)$, alloying $\mathrm{MoSi}_{2}$ with 1 at.\% $\mathrm{Nb}$ increased its yield strength by an order of magnitude compared to pure samples [10]. These alloying strategies may only be utilized successfully if the impurities do not affect oxidation resistance of $\mathrm{MoSi}_{2}$ adversely. Therefore, studies on oxidation resistance should be conducted parallel with investigations on the effects of impurities on mechanical properties of $\mathrm{MoSi}_{2}$.

Outstanding oxidation resistance of $\mathrm{MoSi}_{2}$ above its pesting temperature up to $1700^{\circ} \mathrm{C}$ results from the formation of a protective silica $\left(\mathrm{SiO}_{2}\right)$ layer [15], typical of all $\mathrm{SiO}_{2}$-forming materials. In these materials, $\mathrm{SiO}_{2}$ acts as a barrier against further oxidation [16]. Above the pest oxidation temperature, oxidation behavior of $\mathrm{MoSi}_{2}$ is identical to that of $\mathrm{Si}$ up to $1400^{\circ} \mathrm{C}$ [17]. The kinetics of growth of $\mathrm{SiO}_{2}$ layer on $\mathrm{MoSi}_{2}$ is governed by three processes: (1) transport of the oxidizing species for absorption, (2) diffusion of the oxidant through the oxide layer, and (3) oxidant reaction with the bulk $\mathrm{MoSi}_{2}$ to form $\mathrm{SiO}_{2}$. The solution for the kinetic equations results in a short linear region expressed by [16]:

$$
x=k_{1}(t+\tau),
$$

followed by a long parabolic region described by

$$
x^{2}=k_{\mathrm{p}} t,
$$

where $x$ is the oxide thickness at time $t, \tau$ is the transition time from linear to parabolic oxidation relations, and $k_{1}$ and $k_{\mathrm{p}}$ are the linear and parabolic oxidation rate constants, respectively. The linear rate is due to interfacial reaction-controlled mechanism at short times and parabolic regime is the result of diffusion-controlled mechanism at longer times.

Complexities in the kinetics of oxidation of $\mathrm{MoSi}_{2}$ arise from formation of other $\mathrm{Mo}-\mathrm{Si}$ phases as well as phase transformations in $\mathrm{SiO}_{2}$ scale. Local consumption of $\mathrm{Si}$ 
may result in formation of $\mathrm{Mo}_{5} \mathrm{Si}_{3}$ at low or high temperatures [18-21] but $\mathrm{Mo}_{3} \mathrm{Si}$ has been observed to result from the reaction of $\mathrm{Mo}_{5} \mathrm{Si}_{3}$ with $\mathrm{O}_{2}$ only at low temperatures [22]. At high temperatures, upon rapid formation of a stable oxide layer, $\mathrm{Mo}_{5} \mathrm{Si}_{3}$, which forms beneath the oxide scale, is insulated from oxygen and formation of $\mathrm{Mo}_{3} \mathrm{Si}$ is prevented. Finally, since scale growth is a diffusion-controlled process, the extent of crystallization of $\mathrm{SiO}_{2}$, may affect diffusion rate and, consequently, oxidation mechanism. $\mathrm{Nb}$ seems to be the most potent alloying element for improving mechanical properties of $\mathrm{MoSi}_{2}$ concurrently at low- and high-temperatures.

The present work investigates the effects of $\mathrm{Nb}$ impurities (2 at.\%), on oxidation resistance of $\mathrm{MoSi}_{2}$ at the target application temperatures of the alloy with a focus on developing an $\mathrm{MoSi}_{2}$-based alloy that exhibits low-temperature ductility and enhanced high-temperature strength while retaining and inherently superb oxidation resistance of $\mathrm{MoSi}_{2}$.

\section{Experimental procedure}

Polycrystalline unalloyed $\mathrm{MoSi}_{2}$ and $\left(\mathrm{Mo}_{1-x}, \mathrm{Nb}_{x}\right) \mathrm{Si}_{2}$ buttons with $x=0.015,0.03$, and 0.06 for $0.5,1.0$, and 2.0 at.\% $\mathrm{Nb}$, respectively, were prepared by arc-melting elemental high purity $\mathrm{Mo}, \mathrm{Si}$, and $\mathrm{Nb}$ in an argon atmosphere. Following the results of previous investigations, excess $\mathrm{Si}$ was used to compensate for $\mathrm{Si}$ loss that occurs during arc-melting [13]. The starting composition of the alloys were $\mathrm{MoSi}_{2.01}$ and $\left(\mathrm{Mo}_{1-x}, \mathrm{Nb}_{x}\right) \mathrm{Si}_{2.01}$. Experimental procedure is detailed in previous publications $[10,23,24]$.

\section{Results and discussion}

Cross-sections of $\mathrm{MoSi}_{2}$ samples containing (a) 0.0, (b) 0.5 , (c) 1.0 , and (d) 2.0 at.\% Nb after oxidation for $100 \mathrm{~h}$ at $1700{ }^{\circ} \mathrm{C}$ are shown in Fig. 1 . It should be noted that

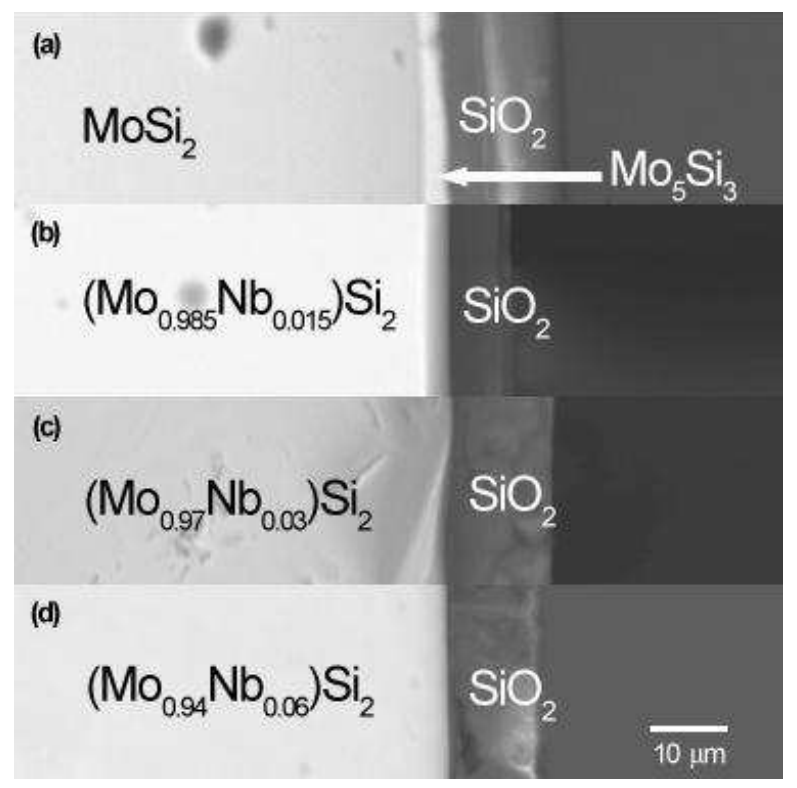

Fig. 1. Comparison of the cross-sections of the oxide scales for all alloys after $100 \mathrm{~h}$ oxidation at $1700^{\circ} \mathrm{C}$.
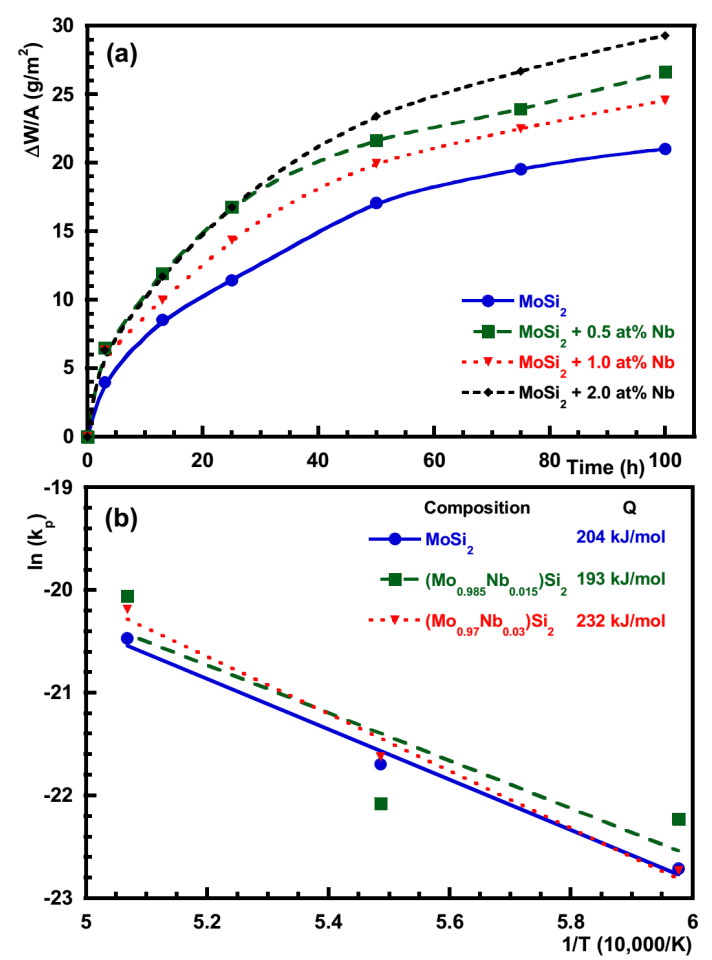

Fig. 2. (a) Results of isothermal oxidation of unalloyed $\mathrm{MoSi}_{2}$ and samples containing $\mathrm{Nb}$ at $1700{ }^{\circ} \mathrm{C}$. (b) Plots of inverse temperature vs. logarithmic parabolic rate constant for calculating activation energy for oxidation. Values of $Q$ for each composition are listed next to the legend.

there was some variation in the oxide thickness from one point on the sample to the next point. The main difference distinguishing oxidation of pure sample from those containing $\mathrm{Nb}$ was the presence of $\mathrm{Mo}_{5} \mathrm{Si}_{3}$ layer in unalloyed samples. Formation of $\mathrm{Mo}_{5} \mathrm{Si}_{3}$ has been reported previously as a byproduct of rapid consumption of Si at the scale/bulk interface at elevated temperatures [23]. $\mathrm{Mo}_{5} \mathrm{Si}_{3}$ was not observed in any $\mathrm{Nb}$-containing sample during investigations reported here. Presence of $\mathrm{Nb}$ impurity could prevent $\mathrm{Mo}_{5} \mathrm{Si}_{3}$ formation if it lowered the oxidation rate of $\mathrm{MoSi}_{2}$, which would allow for diffusion of Mo from Si-starved oxide interface to lower concentrations at the center of the sample.

However, as seen in Fig. 2a, at $1700^{\circ} \mathrm{C} \mathrm{Nb}$ impurity enhanced the oxidation rate of $\mathrm{MoSi}_{2}$. Another mechanism for prevention of $\mathrm{Mo}_{5} \mathrm{Si}_{3}$ formation could be enhanced solubility of Mo in the $\mathrm{MoSi}_{2}$ matrix due to $\mathrm{Nb}$ impurity. $\mathrm{Nb}$-rich regions were observed in all $\mathrm{Nb}$-containing samples after oxidation at $1700^{\circ} \mathrm{C}$ for $100 \mathrm{~h}$. Energy dispersive X-ray spectroscopy (EDS) analysis of these regions in 2 at.\% Nb-containing samples indicated 41.4, 40.2 , and 18.4 at.\% Mo, $\mathrm{Si}$, and $\mathrm{Nb}$, respectively. These values correspond to a $3 / 2$ atomic ratio of $((9 / 13) \mathrm{Mo}+$ $(4 / 13) \mathrm{Nb}) / \mathrm{Si}$ or $((9 / 13) \mathrm{Mo}+(4 / 13) \mathrm{Nb})_{3} \mathrm{Si}_{2} . \mathrm{Mo}_{3} \mathrm{Si}_{2}$ and $\mathrm{Nb}_{3} \mathrm{Si}_{2}$ are metastable phase of $\mathrm{Mo}-\mathrm{Si}$ and $\mathrm{Nb}-\mathrm{Si}$ systems, respectively $[25,26]$. These regions remained scattered in the $\mathrm{MoSi}_{2}$ matrix thus a Si-deficient phase did 
not form in Nb-containing samples beneath the oxide layer as it did in pure $\mathrm{MoSi}_{2}$. The fraction of $((9 / 13) \mathrm{Mo}+$ $(4 / 13) \mathrm{Nb})_{3} \mathrm{Si}_{2}$ phase increased with $\mathrm{Nb}$ content but remained distributed along the grain boundaries in all samples.

The parabolic oxidation rate constants at three test temperatures were calculated from the slope of the plot of time $(t)$ vs. change in specific weight squared $(\Delta W / A)^{2}$ as described by Eq. (2). Using the Arrhenius relation

$$
k_{\mathrm{p}}=k_{0} \exp \left(-\frac{Q}{R T}\right)
$$

for thermally activated oxidation process, the value of activation energy for oxidation $(Q)$ may be calculated from the slope of the line obtained from plot of $1 / \mathrm{T}$ vs. $\ln \left(k_{\mathrm{p}}\right)$. The Arrhenius lines for these calculations are shown in Fig. 2b.
The values of $k_{\mathrm{p}}$ and $Q$ are listed in Table for all samples at $1400^{\circ} \mathrm{C}, 1550{ }^{\circ} \mathrm{C}$, and $1700^{\circ} \mathrm{C}$ except for 2 at. $\% \mathrm{Nb}$ containing alloy at $1400^{\circ} \mathrm{C}$ due to sample failure. Therefore, neither $k_{\mathrm{p}}$ at $1400^{\circ} \mathrm{C}$ nor $Q$ could be calculated for this alloy. Activation energies of 193 and $232 \mathrm{~kJ} / \mathrm{mol}$ were calculated for 0.5 and 1.0 at.\% Nb containing samples, respectively. Comparing the value of $Q$ for unalloyed sample, $204 \mathrm{~kJ} / \mathrm{mol}$, it is clear that $\mathrm{Nb}$ impurity at the level used here, does not alter the rate controlling mechanism for oxidation of $\mathrm{MoSi}_{2}$. The values of activation energies calculated here are within the range of values of activation energy for diffusion of molecular oxygen $\left(\mathrm{O}_{2}\right)$ through vitreous silica [27]. Therefore, diffusion of $\mathrm{O}_{2}$ through the oxide scale is the rate controlling mechanism for oxidation.

Calculated values of parabolic oxidation rate constants $\left(k_{\mathrm{p}}\right)$

TABLE

and activation energies for oxidation $(Q)$.

\begin{tabular}{c|c|c|c|c}
\hline \hline Alloy & $k_{\mathrm{p}}\left(1400^{\circ} \mathrm{C}\right)$ & $k_{\mathrm{p}}\left(1550^{\circ} \mathrm{C}\right)$ & $k_{\mathrm{p}}\left(1700^{\circ} \mathrm{C}\right)$ & $Q[\mathrm{~kJ} / \mathrm{mol}]$ \\
\hline $\mathrm{MoSi}_{2}$ & $1.37 \times 10^{-10}$ & $3.78 \times 10^{-10}$ & $1.29 \times 10^{-9}$ & 204 \\
$\left(\mathrm{Mo}_{0.985}, \mathrm{Nb}_{0.015}\right) \mathrm{Si}_{2}$ & $2.21 \times 10^{-10}$ & $2.59 \times 10^{-10}$ & $1.96 \times 10^{-9}$ & 194 \\
$\left(\mathrm{Mo}_{0.97}, \mathrm{Nb}_{0.03}\right) \mathrm{Si}_{2}$ & $1.34 \times 10^{-10}$ & $4.06 \times 10^{-10}$ & $1.71 \times 10^{-9}$ & 232 \\
$\left(\mathrm{Mo}_{0.94}, \mathrm{Nb}_{0.06}\right) \mathrm{Si}_{2}$ & - & $1.69 \times 10^{-9}$ & $2.44 \times 10^{-9}$ & -
\end{tabular}

Degree of crystallinity of silica would affect the diffusion rate of $\mathrm{O}_{2}$. EDS elemental mapping did not show detectable concentration of $\mathrm{Nb}$ in the silica scale. Therefore, this study could not attribute any change in oxidation behavior of $\mathrm{MoSi}_{2}$ to effects of $\mathrm{Nb}$ on crystallization of $\mathrm{SiO}_{2}$.

Finally, oxidation rate of Nb-containing samples, as shown in Fig. 2a, increased from 1.0 at.\% to 2.0 at.\% Nb impurity. Although $\mathrm{Nb}$ impurity enhanced the rate of oxidation slightly, its effect did not depend on the impurity concentration. The presence of an $\mathrm{Mo}_{5} \mathrm{Si}_{3}$ layer beneath the oxide scale may abate the oxidation rate by creating another barrier for diffusion of $\mathrm{Si}$ to reach the scale/matrix interface. The increase in the rate of oxidation in the samples containing $\mathrm{Nb}$ impurity may be due to elimination of $\mathrm{Mo}_{5} \mathrm{Si}_{3}$ diffusion barrier in the presence of $\mathrm{Nb}$.

\section{Conclusions}

Alloying of $\mathrm{MoSi}_{2}$ by 0.5 , 1.0, and 2.0 at.\% $\mathrm{Nb}$ did not result in significant deterioration of oxidation resistance of the alloy. Diffusion of $\mathrm{O}_{2}$ through the oxide layer remained the rate controlling mechanism with or without Nb impurity. Since previous investigations have shown that minor $\mathrm{Nb}$ alloying produces significant improvements in mechanical properties of $\mathrm{MoSi}_{2}$, herein, it is concluded that $\mathrm{Nb}$-alloying may be the path towards developing a viable $\mathrm{MoSi}_{2}$-based alloy with ambient temperature ductility, high strengths at ultrahigh temperatures, and excellent oxidation resistance up to $1700^{\circ} \mathrm{C}$.

\section{Acknowledgments}

SEM investigations were made possible through the use of ESEM procured by National Science Foundation MRI grant number CMS-0321226. This research was, in part, supported by the National Science Foundation CREST grant HRD-0932421.

\section{References}

[1] A.K. Vasudevan, J.J. Petrovic, Mater. Sci. Eng. A 155, 1 (1992)

[2] J.J. Petrovic, Ceram. Eng. Sci. Proc. 18, 3 (1997).

[3] M.G. Hebsur, M.V. Nathal, Structural Intermetallics, The Minerals, Metals and Materials Society, Warrendale (PA) 1997, p. 949.

[4] K. Kurokawa, H. Houzumi, I. Saeki, H. Takahashi, Mater. Sci. Eng. A 261, 292 (1999).

[5] S. Bose, Mater. Sci. Eng. A 155, 217 (1992).

[6] H. Inui, T. Nakamoto, K. Ishikawa, M. Yamaguchi, Mater. Sci. Eng. A 261, 131 (1999).

[7] Y. Umakoshi, T. Nakano, K. Kishimoto, D. Furuta, K. Hagihara, M. Azuma, Mater. Sci. Eng. A 261, 113 (1999). 
[8] U.V. Waghmare, E. Kaxiras, V.V. Bulatov, M.S. Duesbery, Modeling Simul. Mater. Sci. Eng. 6, 493 (1998).

[9] A. Misra, A.A. Sharif, J.J. Petrovic, T.E. Mitchell, Acta Mater. 48, 925 (2000).

[10] A.A. Sharif, A. Misra, T.E. Mitchell, Mater. Sci. Eng. A 358, 289 (2003).

[11] A.A. Sharif, J.J. Petrovic, A. Misra, T.E. Mitchell, in: Annual Meeting of the American Ceramic Society, Eds.: J.P. Singh, N.P. Bansal, A. Bandyopadhyay, American Ceramic Society, Philadelphia 2000, p. 69 .

[12] A.A. Sharif, A. Misra, J.J. Petrovic, T.E. Mitchell, Scr. Mater. 44, 879 (2001).

[13] A.A. Sharif, A. Misra, J.J. Petrovic, T.E. Mitchell, Intermetallics 9, 869 (2001).

[14] A.A. Sharif, A. Misra, T.E. Mitchell, Scr. Mater. 52, 399 (2005).

[15] J. Schlichting, Mater. Chem. 4, 93 (1979).

[16] B.E. Deal, A.S. Grove, J. Appl. Phys. 36, 3770 (1965).

[17] H.J. Grabke, G.H. Meier, Oxid. Metals 44, 147 (1995).
[18] K. Ito, T. Hayashi, M. Yokobayashi, H. Numakura, Intermetallics 12, 407 (2004).

[19] Y.T. Zhu, M. Stan, S.D. Conzone, D.P. Butt, J. Am. Ceram. Soc. 82, 2785 (1999).

[20] C.D. Wirkus, D.R. Wilder, J. Am. Ceram. Soc. 49, 173 (1966)

[21] J.B. Berkowitz-Mattuk, R.R. Dils, J. Electrochem. Soc. 112, 583 (1965).

[22] K. Natesan, S.C. Deevi, Intermetallics 8, 1147 (2000).

[23] A.A. Sharif, J. Mater. Sci. 45, 865 (2010).

[24] A.A. Sharif, J. Alloys Comp. 518, 22 (2012).

[25] N. Ponweiser, W. Paschinger, A. Ritscher, J.C. Schuster, K.W. Richter, Intermetallics 19, 409 (2011).

[26] M. Li, L. Song, J. Le, X. Zhang, B. Pei, X. Hu, Mater. Trans. 45, 2785 (2004).

[27] M.L.F. Nascimento, E.D. Zanotto, Phys. Chem. Glasses: Eur. J. Glass Sci. Technol. B 48, 201 (2007). 